\title{
Evaluation of Gain and Quality Factor of an Erbium Doped Fiber Post-, Pre- and in-line Amplifier for GPON
}

\author{
Bentahar Attaouia \\ Department of electronic \\ University of Djillali Liabès \\ Sidi Bel-Abbès, Algeria
}

\author{
Kandouci Malika \\ Department of electronic \\ University of Djillali Liabès \\ Sidi Bel-Abbès, Algeria
}

\author{
Christelle Aupetit-. \\ Berthelemot, \\ University of Limoges, \\ France
}

\begin{abstract}
Erbium Doped Fiber Amplifiers (EDFA) have become more popular in optical networks. The concept of extending the reach to $60 \mathrm{~km}$ of GPON with a 1:64 split ratio through the introduction of amplification (EDFA) designed for $1550 \mathrm{~nm}$ in downstream is presented with simulation of GPON Optical Network in terms of different parameter (fiber length, signal input power, number of users, splitter loss...). Moreover in this paper, was study different characterizations of EDFA amplifier, which depend essentially on the opt-geometric parameters, such as concentrations of ions erbium, length of the erbium doped and core radium fiber and the effect of those parameters to optimize the gain $G$ and quality factor $Q$ for different amplifier ( post-, pre- and line amplification) configurations in GPON system.
\end{abstract}

\section{General Terms}

Amplification, GPON

\section{Keywords}

GPON, Access network, Amplifier optic, Erbium doped fiber amplifier, Reach of passive optical network.

\section{INTRODUCTION}

The relentless use of multimedia services through the Internet highlights a growing need for higher bandwidths in access networks, inducing a fiber massive deployment increasingly closer to end user. Bandwidth-hungry services such as high definition telepresence, telemedicine and remote surgery, online gaming, 3D and HD video broadcasting, personal cloud storage systems and the increasing number of mobile devices allowing ubiquitous connectivity (anytime, anywhere) are some examples that point out the importance of providing higher and higher throughputs.

The Passive Optical Network (PON) is the solution retained by operators for the fiber-to-the-home (FTTH) technology [1]. Recently standardization bodies (IEEE, FSAN) have specified normalization for PONs for FTTH that permits a splitting ratio up to 32 in the case of EPON and up to 64 users for Gigabit Passive Optical Network (GPON). This is mainly limited: on the one hand, by the bandwidth sharing level, on the other hand, by the splitter loss [2]. The insertion of active elements to the Access Network and especially optical amplification by SOAs, EDFAs or any other, in general, rareearth Doped fiber amplifier can provide a solution for overcoming the increasing splitting ratio[1],[2] .

In order to increase the distance or the splitting ratio, recent papers have demonstrated by simulations optical amplification in access architectures by using Erbium Doped Fiber Amplifier (EDFA). In this paper, we shall investigate the use of EDFA amplifiers in order to extend the optical budget of GPON system. This system can deserve 64 users with $60 \mathrm{~km}$ reach. The EDFA characteristics are also presented as a function of signal input power. The performance characteristics like Q factor, bit error rate BER, eye diagrams and eye closure penalty are studied by simulating different position for amplifier ( post-, pre- and in-line amplification) methods in GPON system.

\section{GPON AMPLIFIER}

GPON is an all-optical transmission based network which aims at providing a high speed network connection. The characteristics of GPON technology has been standardized by International Telecommunication Union-T (ITU-T) in recommendation G.984 series [3]. The downstream and upstream traffics are transmitted at $1490 \mathrm{~nm}$ and $1310 \mathrm{~nm}$ while $1550 \mathrm{~nm}$ wavelength is allocated for video. The physical configurations can be seen in term of splitting ratio and the distance of OLT-ONT. Theoretically, the splits can be up to 64 but due to the current hardware limitations, the development so far can only reach 32 and the maximum physical length from the OLT to ONT is $20 \mathrm{~km}$ [4], [12]. To cover a wider area and get more power margin in order to decrease the number of OLTs, an amplification scheme adapted to PON systems is required [13].

Various optical amplifiers, such as erbium-doped fiber amplifier (EDFA), semiconductor optical amplifier (SOA) and Raman amplifier, could provide an extended reach and/or a high split-ratio for the cost-effective implementation of PONs. Development of other types of DFAs for amplification in the remaining optical bands has been actively investigated. Praseodymium-doped fiber amplifiers (PDFAs for upstream) and thulium-doped fiber amplifiers (TDFAs for downstream) were developed to amplify signals around 1300 and $1490 \mathrm{~nm}$, respectively [5], [6].

Erbium doped fiber amplifier (EDFA) is capable to amplify light in the $1550 \mathrm{~nm}$ wavelength region (where the attenuation of silica fiber is minimum). Improvements that GPON offers respecting all of its previous standards is, in general, increasing the bandwidth in transmission and providing security to the own network by protocol level Erbium-doped fiber amplifiers (EDFAs) furnish optical amplification to compensate power loss in optical signal transmission and are attractive candidates for GPON reach extension. They can be designed to provide low noise figure (NF), and fast gain dynamics in the $1550 \mathrm{~nm}$ (C-band) and $1490 \mathrm{~nm}$ (S-band) windows used by GPON.

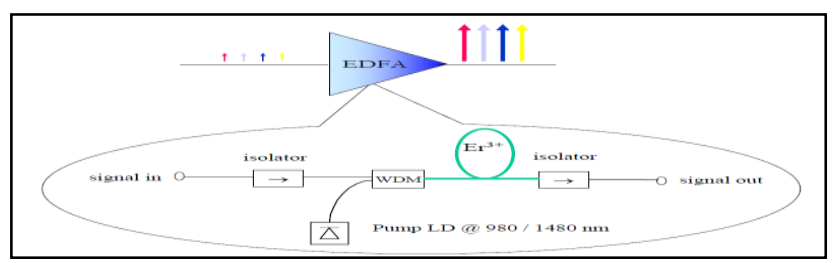

Fig1: Block diagram of Erbium Doped Fiber Amplifier 
The optical amplifier EDFA is constituted of doped amplified fiber and laser pump coupled by an optical multiplexer (Fig.1). The fiber is doped with erbium, a rare earth element that has the appropriate energy levels in their atomic structures for amplifying light. EDFAs are designed to amplify light at $1550 \mathrm{~nm}$. The device utilizes a $980 \mathrm{~nm}$ or $1480 \mathrm{~nm}$ pump laser to inject energy into the doped fiber. When a weak signal at $1310 \mathrm{~nm}$ or $1550 \mathrm{~nm}$ enters the fiber, the light stimulates the rare earth atoms to release their stored energy as additional $1550 \mathrm{~nm}$ or $1310 \mathrm{~nm}$ light. This process continues as the signal passes down the fiber, growing stronger and stronger as it goes [7], [8].

\section{THE SIMULATED CHAIN AND RESULTS}

Figure. 2 shows the schematic of the GPON bidirectional architecture which can be implemented with a splitting ratio of 64 with $19 \mathrm{~dB}$ of loss. The OLT (Optical Line Terminal) and ONT (Optical Network Terminal) emitters consist of DFB lasers and the receivers are avalanche photodiodes (APD) for the OLT and PIN photodiode for the ONT. The procedure for data transmission in GPON networks depends on the direction of the communications. Downstream transmission (from the central office (OLT) to the subscribers (ONTs)) with wavelength of $1550 \mathrm{~nm}$ and $2.5 \mathrm{Gbits} / \mathrm{s}$ employs TDM (Time Division Multiplexing) to broadcast the signal to all the ONTs sharing the same fiber. ONTs filter the received data and extract only their own traffic.

The upstream channels (reverse side) with wavelength of $1310 \mathrm{~nm}$ and $1.25 \mathrm{Gbits} / \mathrm{s}$ are combined using a multiple access protocol such as TDMA (Time Division Multiple Access), in which each ONT transmits in an assigned time slot windows to avoid collisions, and the OLT controls the upward capacity assigning bandwidth for all users [9],[10].

Erbium doped optical amplifiers (EDFA) have been chosen for the simulation in order to amplify wavelength around 1550 $\mathrm{nm}$ for threes positions (pre-, post- and in line-amplification). The downstream optical amplifications can be easily shared amongst multiple ONTs. However, to share an upstream amplifier could be challenging because ONUs are located at different distance with different losses to the optical amplifier. In addition, upstream data are sent in burst mode, requiring optical amplifier to have fast transient control capabilities [11]. The optical output power from both the OLT and the ONT was set at $10 \mathrm{dBm}$. A bidirectional single mode optical fiber (SMF G652) with an attenuation coefficient of 0.2 $\mathrm{dB} / \mathrm{km}$ and length of $60 \mathrm{~km}$ for all wavelengths was connected to the output port from the OLT.

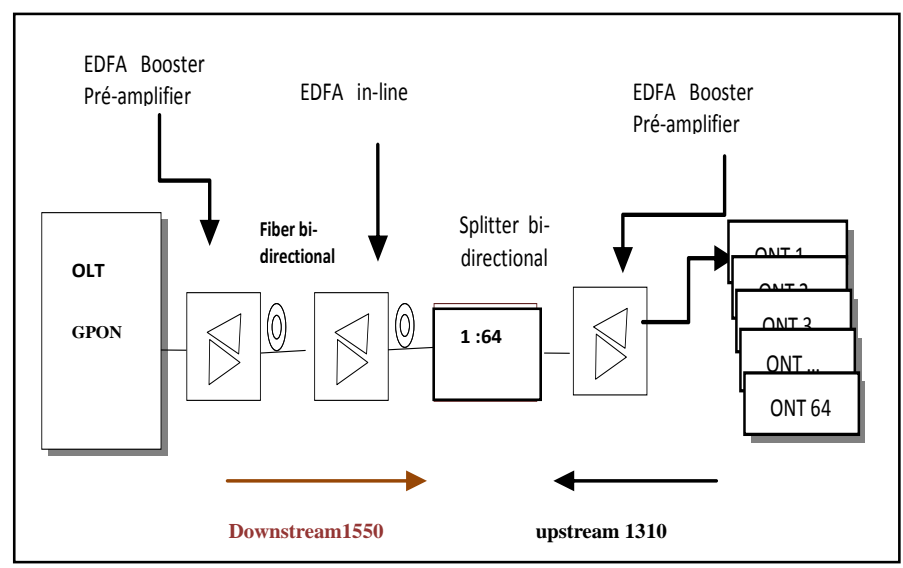

Fig2: Architecture of GPON bi-directional with EDFA
In this part, we present the gain characteristic and noise figure NF of Erbium Doped Fiber Amplifier post- , pre- and in-line amplifier in terms of the signal input power, amplifier length, erbium ions concentration, amplifier fiber diameter(core radium). The effects of these quantities on the action and performance of erbium amplifiers such as amplifier gain, noise figure and $\mathrm{Q}$ factor amplifier are investigated. The flowing parameters values used are summarized in Table1:

Table 1: Represents the Typical EDFA Parameters

\begin{tabular}{|l|l|l|}
\hline \multicolumn{1}{|c|}{ Parameter } & \multicolumn{1}{c|}{ Value } & Symbol \\
\hline Signal input power & 0 to $10 \mathrm{dBm}$ & $\mathrm{P}_{\text {in }}$ \\
\hline Pump wavelength & $980 \mathrm{~nm}$ & $\chi$ \\
\hline Pump power & $200 \mathrm{mw}$ & $\mathrm{P}_{\mathrm{p}}$ \\
\hline Amplifier length & 2 to $30 \mathrm{~m}$ & $\mathrm{~L}_{\text {edfa }}$ \\
\hline core diameter & 2.2 to $8 \mu \mathrm{m}$ & $\mathrm{D}$ \\
\hline Erbium ion concentration & $\begin{array}{l}2 \mathrm{e}+24 / \mathrm{m}^{-3} \text { to } \\
2 \mathrm{e}+25 / \mathrm{m}^{-3}\end{array}$ & $\mathrm{C}$ \\
& & \\
\hline
\end{tabular}

\subsection{Booster}

EDFA considered as a booster is connected directly behind the transmitter. Its function is to increase a high power input signal prior to transmission and to enhance the transmitted power level or to compensate for the losses of optical elements between the laser and optical fibers, such as optical coupler [10]. We will study the effect of different parameters such length amplifier (Ledfa) and concentration of erbium ions (C) and core radium (D) to optimize the gain and quality factor characterizations of EDFA amplifier in position booster with fixed pump power.

Firstly, the amplifier length is varied for threes values ( Ledfa $=5,15$ and $25 \mathrm{~m}$ ), the concentration of erbium and core radium are fixed at $\mathrm{C}=1 \mathrm{e}+025 / \mathrm{m}-3$ and $\mathrm{D}=2.2 \mu \mathrm{m}$ respectably (figure3). Secondly, the concentration is varied for threes values $(\mathrm{C}=2 \mathrm{e}+24 / \mathrm{m}-3,7 \mathrm{e}+24 / \mathrm{m}-3$ and $2 \mathrm{e}+25 /$ m-3 ), the amplifier length and core radium are fixed at Ledfa $=10 \mathrm{~m}$ and $\mathrm{D}=2.2 \mu \mathrm{m}$ respectably (figure 4 ). Thirdly the core radium is varied for threes values $(\mathrm{D}=2.2 \mu \mathrm{m} 5$ and $8 \mu \mathrm{m})$, the concentration of erbium and amplifier length are fixed at $\mathrm{C}=1 \mathrm{e}+025 / \mathrm{m}-3$ and $\mathrm{Ledfa}=10 \mathrm{~m}$ respectably (figure 5)

Max. Q Factor (Power (dBm) )

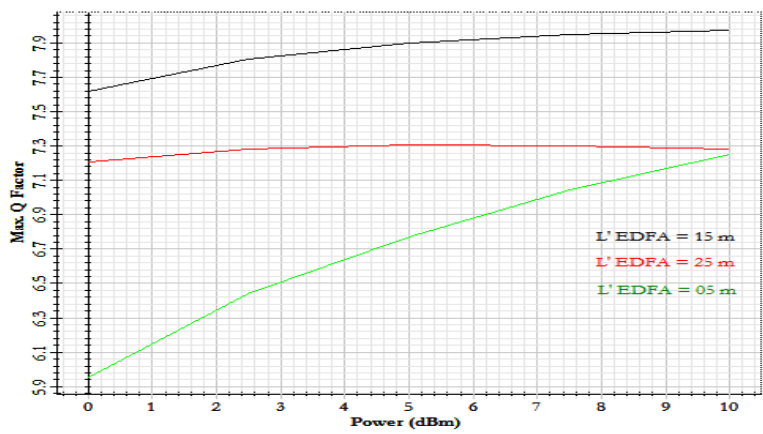

Fig 3: Q factor as a function of signal input power for threes amplifier length 


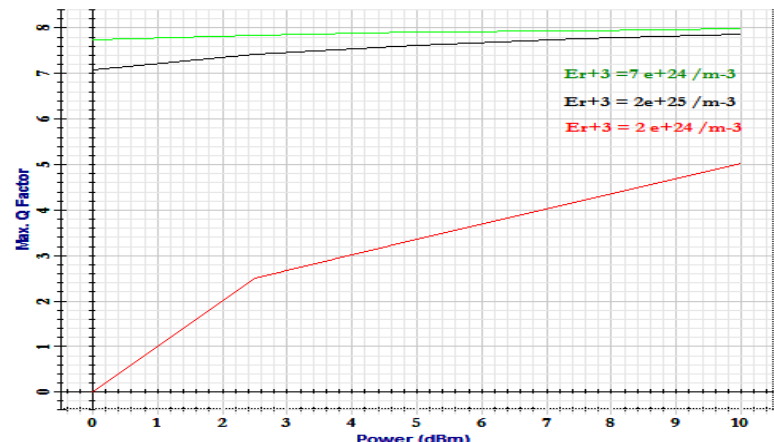

Fig 4: Q factor as a function of signal input power for threes concentrations

Max. Q Factor (Power (dBm) )

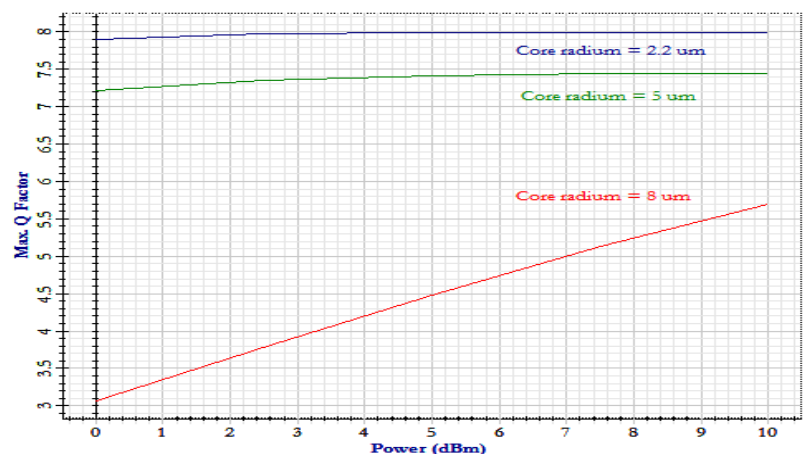

Fig : $5 \mathrm{Q}$ factor as a function of signal input power for threes core radium.

According to the above figures we can see the variation of the quality factor $\mathrm{Q}$ with the signal input power for different values of length amplifier $\left(\mathrm{L}_{\text {edfa }}\right)$, concentration of erbium ions (C) and core radium (D). Were maximum Q factor of 7.94 was obtained when concentration and core radium are fixed $\mathrm{C}=1 \mathrm{e}+25 / \mathrm{m}^{-3}, \mathrm{D}=2.2 \mu \mathrm{m}$ and $\mathrm{L}_{\text {edfa }}=15 \mathrm{~m}$ (see figure 3), however a $\mathrm{Q}$ factor of 7.98 is obtained for $\mathrm{C}=7 \mathrm{e}+24 / \mathrm{m}^{-3}$ and $L_{\text {edfa }}=10 \mathrm{~m}$ and $\mathrm{D}=2.2 \mu \mathrm{m}$ (see figure 4 ), an optimum value of $\mathrm{Q}$ factor around of 8 found for $\mathrm{C}=1 \mathrm{e}+25 / \mathrm{m}^{-3}$ et $\mathrm{L}_{\text {edfa }}=10 \mathrm{~m}$ et $\mathrm{D}=2.2 \mu \mathrm{m}$ ( see figure 5 ).

Gain(dB),Noise Figure (dB) (Power (dBm) )

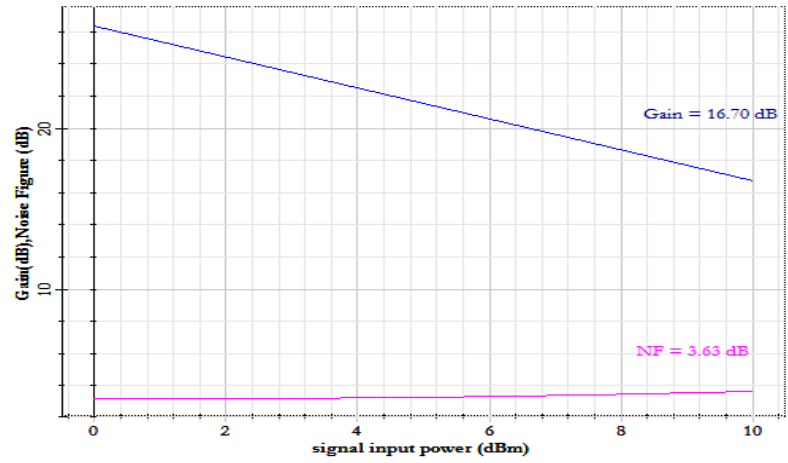

Fig 6: Gain and noise figure NF as a function of signal input power for EDFA in position booster.
Figure6 illustrate the variation of the gain $\mathrm{G}$ and noise figure $\mathrm{NF}$ as a function of the signal input power. We can see that the increase in the signal input power induces a decreases in the amplifier gain and that for a given signal input power of 10 $\mathrm{dBm}$ an amplifier diameter core of $2.2 \mu \mathrm{m}$, a length (fiber doped erbium length) of $10 \mathrm{~m}$ and a concentration of erbium ions of about $1 \mathrm{e}+25 / \mathrm{m}^{-3}$ permit to obtain $\mathrm{G}=16.70$ $\mathrm{dB}$ and $\mathrm{NF}=3.63 \mathrm{~dB}$, this gain and noise figure provides a optimum edfa used in position booster with $\mathrm{Q}$ factor around 8 . One can notice that when the EDFA is used as a booster, non linear effects of the fiber can be activated as the power at the input of the fiber is increased.

\subsection{Pre-amplifier}

In this section we consider the use of an erbium doped fiber amplifier as a pre-amplifier for an optical receiver in order to increase the sensitivity. We will repeat the same simulations

$$
\text { Max. Q Factor (Power (dBm) ) }
$$

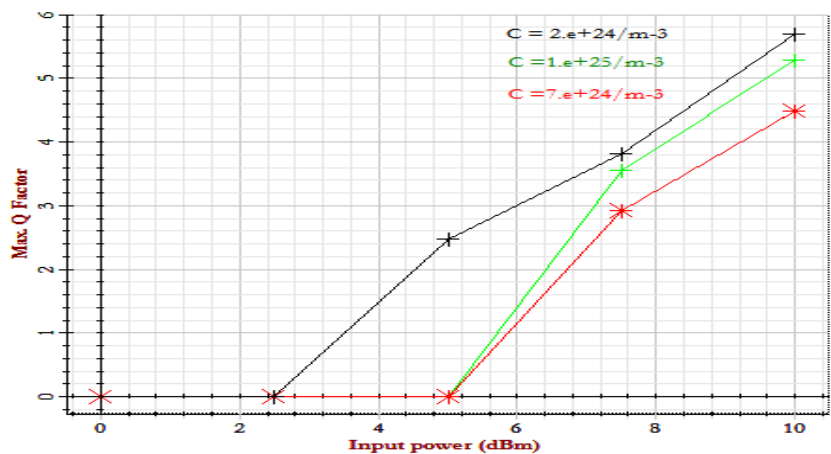

Fig7: Q factor as a function of signal input power for threes concentrations

Max, Q Factor (Power (dBm))

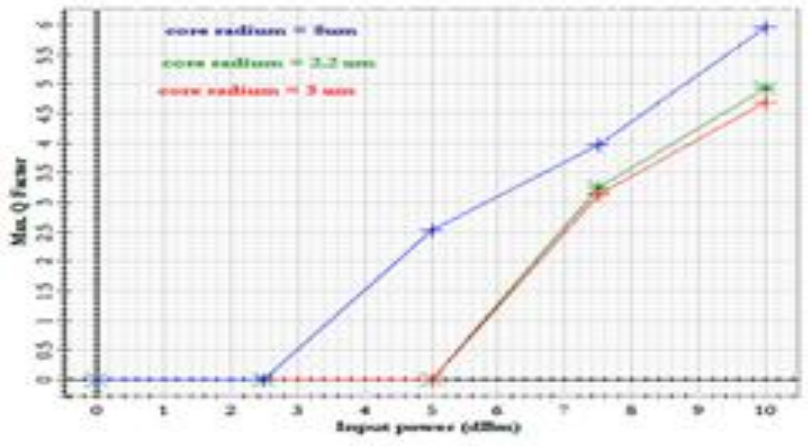

Fig 8: Q factor as a function of signal input power for threes core radium.

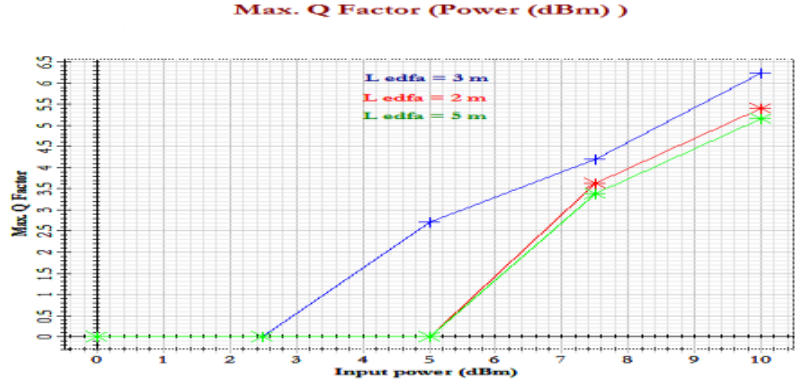

Fig 9: $Q$ factor as a function of signal input power for threes amplifier length. 
The figure 7, 8 and 9 show the graphical representation of $\mathrm{Q}$ value at varied input power ( 0 to $10 \mathrm{dBm}$ ), the pump power is fixed at $200 \mathrm{mw}$. The optical signal is applied with different parameters (length amplifier $\mathrm{L}_{\text {edfa, }}$, concentration of erbium ions $\mathrm{C}$ and core radium $\mathrm{D}$ ) in order to observe the performance of EDFA. Again at $10 \mathrm{dBm}$, EDFA pre-amplifier provides a $\mathrm{Q}$ factor of 0 for signal input power value lower of $2.5 \mathrm{dBm}$, however the $\mathrm{Q}$ factor linearly increases when the signal input power is higher than this value. Other for the signal input power higher than $2.5 \mathrm{dBm}$ and when $\mathrm{C}=2 \mathrm{e}+24 / \mathrm{m}^{-3}, \mathrm{~L}_{\text {edfa }}=10 \mathrm{~m}$ and $\mathrm{D}=2.2 \mu \mathrm{m}$ a $\mathrm{Q}$ factor of 5.90 ( see figure 7) is obtained. However concentration C of $1 \mathrm{e}+25 / \mathrm{m}-3$, Ledfa of $10 \mathrm{~m}$ and D of $8 \mu \mathrm{m}$ provide $\mathrm{Q}$ factor of 6 (see figure 8), an optimum value of $Q$ factor around of 6.24 is found when $C=1 \mathrm{e}+25 / \mathrm{m}$ 3 et Ledfa $=3 \mathrm{~m}$ et $\mathrm{D}=2.2 \mu \mathrm{m}$ ( see figure 9).

Gain(dB), No1se Figure (dB) (Yower (dBm))

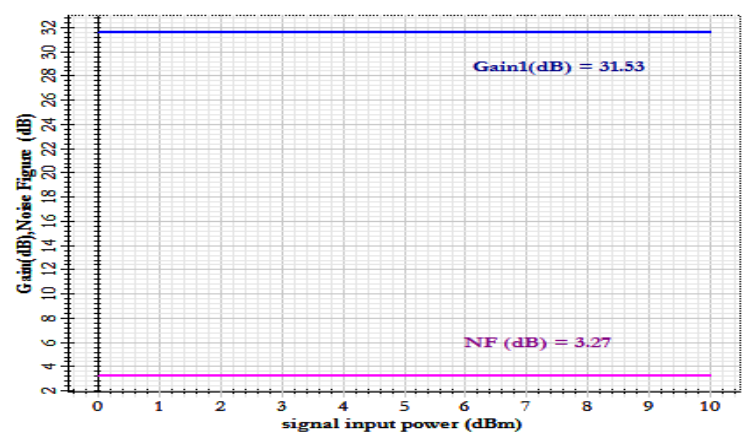

Fig10: Gain and noise figure NF as a function of signal input power for EDFA pre-amplifier.

Figure 10 illustrate the fixed gain $\mathrm{G}$ and noise figure NF as a function of the signal input power, we can see that for EDFA at $10 \mathrm{dBm}$ the core radium must be $2,2 \mu \mathrm{m}$, the amplifier length $\mathrm{L}_{\text {edfa }}$ must be $3 \mathrm{~m}$ and the concentration of erbium active ions is about $1 \mathrm{e}+25 / \mathrm{m}-3$ we found $\mathrm{G}$ of $31,53 \mathrm{~dB}$ and NF of $3,27 \mathrm{~dB}$ . Those values can provide the optimum EDFA used in position pre-amplifier with $\mathrm{Q}=6,24$

\subsection{In-line amplifier}

The in-line amplifiers are placed all along the transmission channel to compensate for the losses incurred during propagation of optical signal. In this section we consider the use of an erbium doped fiber amplifier as a in-line amplifier position and we will repeat the same simulations.

Max. Q Factor (Power (dBm) )

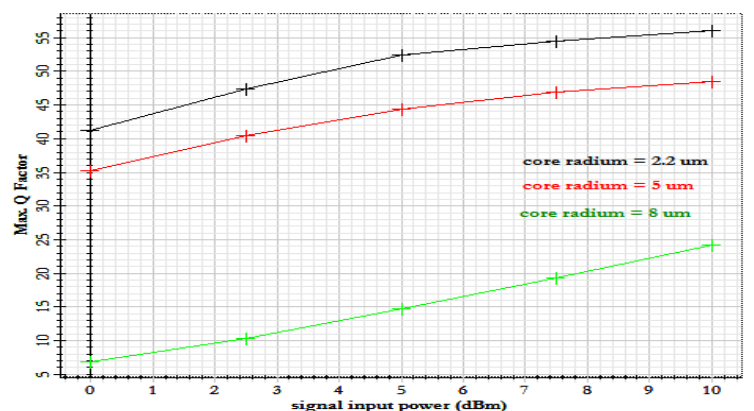

Fig 11: $Q$ factor as a function of signal input power for threes core radium.

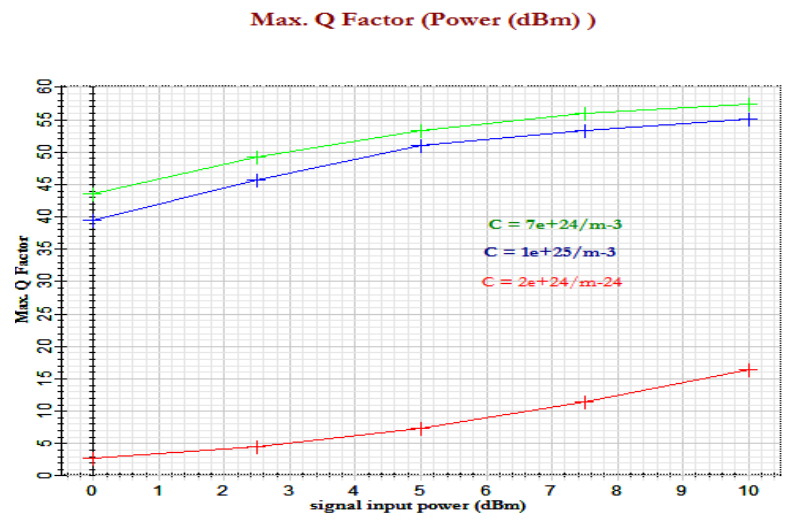

Fig 12: $Q$ factor as a function of signal input power for threes concentrations.

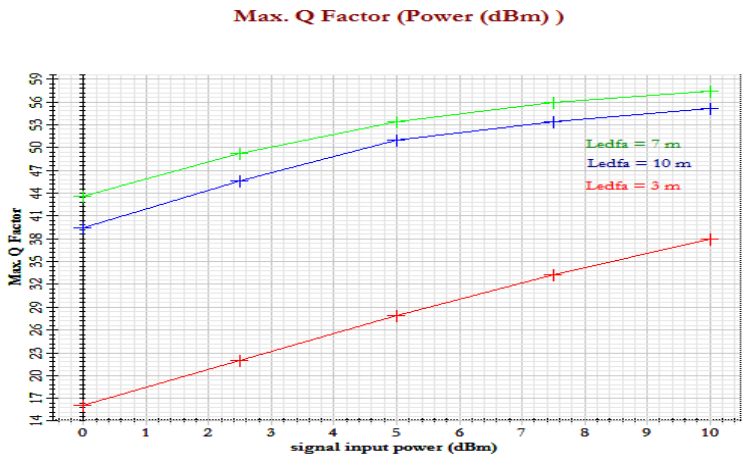

Fig13: $Q$ factor as a function of signal input power for threes amplifier length.

Figures above shows the graphical representation of $\mathrm{Q}$ value by sweeping signal input power ( 0 to $10 \mathrm{dBm})$. It can be seen that for sufficiently large pump power $\left(\mathrm{P}_{\mathrm{p}}=200 \mathrm{mw}\right)$, the $\mathrm{Q}$ factor linearly increases with the signal input power for in-line amplifier. Other for signal input power of $10 \mathrm{dBm}$ and when $\mathrm{C}$ $=1 \mathrm{e}+25 / \mathrm{m}^{-3}, \mathrm{~L}_{\text {edfa }}=10 \mathrm{~m}$ and $\mathrm{D}=2.2 \mu \mathrm{m}$ the $\mathrm{Q}$ factor of 56 (see figure11)is obtained. However when concentration $\mathrm{C}=7 \mathrm{e}$ $+24 / \mathrm{m}^{-3}, \mathrm{~L}_{\text {edfa }}$ of $10 \mathrm{~m}$ and $\mathrm{D}$ of $2.2 \mu \mathrm{m}$ a $\mathrm{Q}$ factor of 57.2 is reached (see figure 12), an optimum value of $\mathrm{Q}$ factor around of 57.53 is found when $\mathrm{C}=1 \mathrm{e}+25 / \mathrm{m}^{-3}$ et $\mathrm{L}_{\text {edfa }}=7 \mathrm{~m}$ et $\mathrm{D}=2.2$ $\mu \mathrm{m}$ (see figure13).

Gain (dB), Noise figure (Power (dBm) )

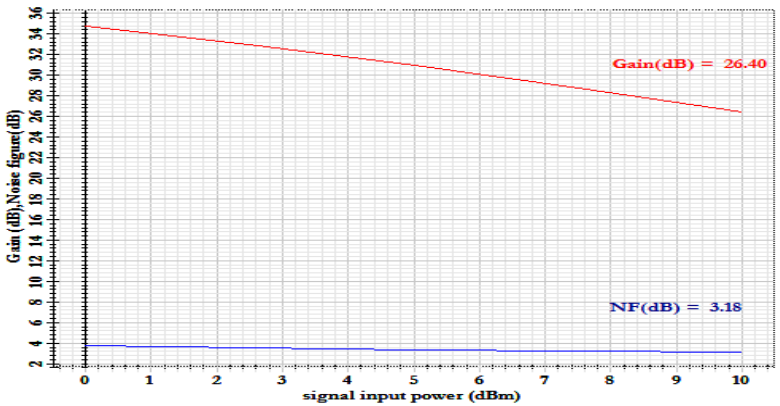

Fig 14 : Gain and noise figure NF as a function signal input power for EDFA in position in-line amplifier 
The figure.14 shown in two different graphs gain and noise figure as a function of signal input power. It can be notice that gain value of $26.40 \mathrm{~dB}$ and noise figure of $3.18 \mathrm{~dB}$ is obtained when the input power is $10 \mathrm{dBm}$ with a diameter core equal to $2.2 \mu \mathrm{m}$,fiber doped erbium length equal to $7 \mathrm{~m}$ and the concentration of erbium active ions of about $1 \mathrm{e}+25 / \mathrm{m}^{-3}$ for the optimum EDFA used in position in-line amplifier with $\mathrm{Q}=$ 57.53

\subsection{Comparison of pre-, post- and in-line EDFA amplifier}

The optical signal is applied to different position in order to observe the performance of EDFA amplifiers. Figure 15 shows variation of $\mathrm{Q}$ factor as a function of the signal input power (0 to $10 \mathrm{dBm}$ ). Again EDFA at $10 \mathrm{dBm}$ used as a booster provides a fixed $\mathrm{Q}$ factor of7.99, while Q-factor increase with the signal input power when the EDFA is in-line (Q factor reaches 57.53) but for pre-amplifier position the least $\mathrm{Q}$ factor (6.24) is obtained. However for input power lower of $2.5 \mathrm{dBm}$ we can notice that $\mathrm{Q}$ factor of 0 .

$$
\text { Max. Q Factor (Power (dBm) ) }
$$

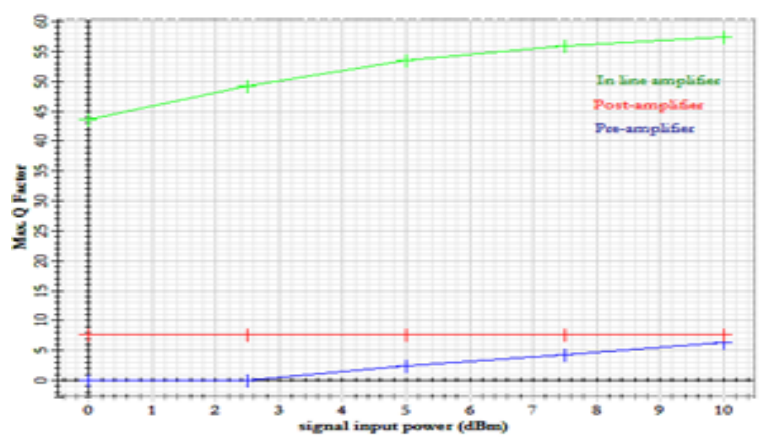

Fig 15: $Q$ factor as a function of signal input power for inline amplifier, booster and preamplifier

Figure 16 above shows the comparison of the eye diagram and the simulation result with EDFA amplification in-line, booster and preamplifier respectively at $10 \mathrm{dBm}$ downstream and for a fiber length of $60 \mathrm{~km}$. We can notice that the best result it given with EDFA in-line amplifier (high Q factor and good eye opening) followed by booster (accepted $\mathrm{Q}$ factor and eye opening), where lower value of $\mathrm{Q}$ and high closure eye for pre-amplifier.
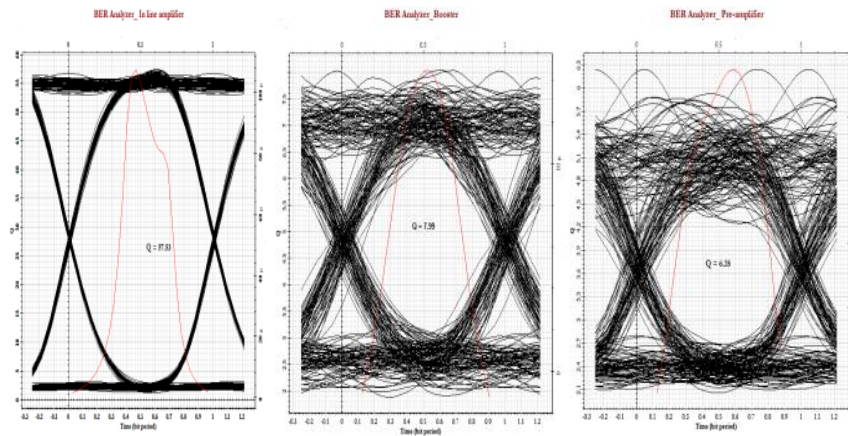

Fig 16: Eye diagram for in-line amplifier, booster and preamplifier EDFA position
Table 2: Comparison of pre-, post- and in-line EDFA amplifier

\begin{tabular}{|c|c|c|c|}
\hline Analysis & Booster & In-line & Pre-amplifier \\
\hline Max Q factor & 7.9998 & 57.53 & 6.24037 \\
\hline Min BER & $4.35 \mathrm{e}-016$ & 0 & $1.72 \mathrm{e}-010$ \\
\hline Eye Height & $7.214 \mathrm{e}-006$ & $9.460 \mathrm{e}-005$ & $2.166 \mathrm{e}-005$ \\
\hline Threshold & $5.538 \mathrm{e}-006$ & $4.196 \mathrm{e}-005$ & $2.344 \mathrm{e}-005$ \\
\hline
\end{tabular}

Table. 2 compares the values of the previously defined amplification configuration using simulation in the context of the GPON. It shows that in-line amplification has better min BER and Q factor when compared with pre-, post-amplifier.

\subsubsection{The effect of the splitter loss}

The splitter is available in variety of splitting ratios, including 1:8, 1:16 and 1:32. Both Planar Light wave Circuit (PLC) splitter and Fused Biotical Taper (FBT) splitter are used in GPON network. One type of 1:64 PLC splitters split introduces $21 \mathrm{~dB}$ losses in both splitter directions, the evolution of quality factor Q as a function of splitter loss is illustrated in figure17.

$$
\text { Max. Q Factoe (Insertion loss (AB)) }
$$

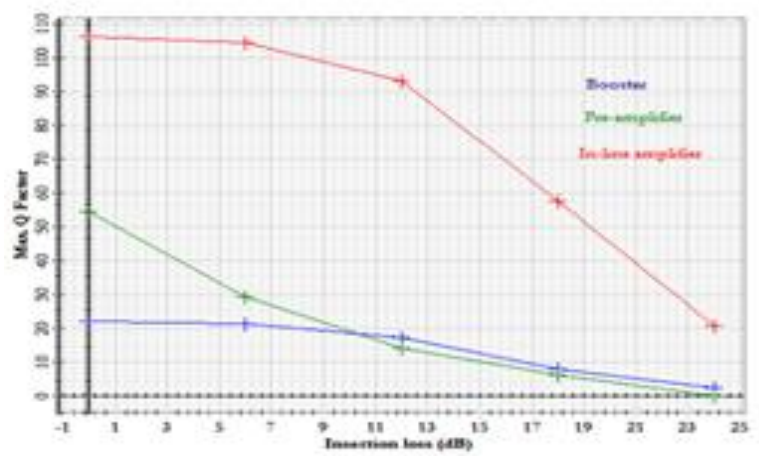

Fig 17: $Q$ factor as a function of splitter loss for in-line amplifier, booster and pre-amplifier EDFA position.

The $\mathrm{Q}$ factor is measured for different position of the EDFA (booster, in- line and preamplifier). We can see that in-line amplifier and preamplifier using EDFA, Q factor decreases linearly and rapidly as the loss splitter increases, while in EDFA booster the decrease happens gradually and in small amount. Other for splitter loss lower of $11 \mathrm{~dB}$,EDFA preamplifier provides Q factor better of EDFA booster, but up of this value the reverse phenomenon is observed .For 10 $\mathrm{dB}$ losses value the best and same Q factor of 20 for booster and preamplifier is founded.

\subsubsection{The effect of the fiber length.}

Figure.18. shows comparison of the Max Q factor in the downstream as a function of fiber length with the three amplification configurations previously exposed. This figure is obtained by sweeping the fiber length from 0 to $60 \mathrm{~km}$. It is seen that the quality factor is best in case of EDFA using inline as compared to post- and pre-amplifier and since the length fiber increases, the $\mathrm{Q}$ factor decreases. This can be explained by the fact that when booster configuration is used, non linear effects are active in the fiber. Moreover, when preamplification is considered the input power of the EDFA is 
very small and ASE noise takes a important part in the degradation of the signal. Considering in-line configuration, these two phenomena are not dominant. High values of Q factor at $60 \mathrm{~km}$ for GPON using in-line EDFA are obtained, followed by booster configuration, while the lower value of $Q$ of 6.24 is obtained with EDFA preamplifier.

Max. Q Factor ( Fiber length $(\mathrm{km})$ )

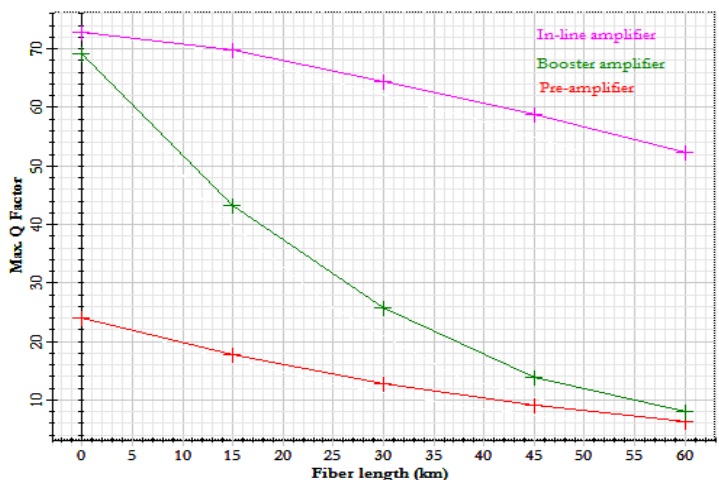

Fig 18 : $Q$ factor as a function of fiber length for in-line amplifier, booster and pre-amplifier.

\section{CONCLUSION}

This work have shown the characterization of EDFA amplifier used in a standard GPON budget extension for 64 users and increase reach to $60 \mathrm{~km}$ an terms of quality factor $\mathrm{Q}$ and gain amplifier $\mathrm{G}$ for threes configurations (preamplifier, booster and in-line amplifier).So the knowledge of optimal values of the erbium doped fiber amplifier parameters like amplifier length $\left(\mathrm{L}_{\text {edfa }}\right)$, core radium $(D)$ and concentrations of erbium ions (C) is necessary to estimate the value of the $\mathrm{Q}$ factor and to optimize the gain and it's noise figure NF. Our analyses show:

1. First and in signal input of $10 \mathrm{dBm}$, our analysis shows that for the optimum EDFA used in position booster with $\mathrm{Q}=8$, the radium core must be $2.2 \mu \mathrm{m}$, amplifier length (fiber doped erbium length) $10 \mathrm{~m}$ and the concentration of erbium active ions is about $1 \mathrm{e}+25 / \mathrm{m}^{-3}$ when the gain obtained is $16.70 \mathrm{~dB}$ and noise figure factor NF is $3.63 \mathrm{~dB}$.

2. While for EDFA with $\mathrm{C}=1 \mathrm{e}+25 / \mathrm{m}^{-3}, \mathrm{~L}_{\text {edfa }}=7 \mathrm{~m}$ and $\mathrm{D}=2.2 \mu \mathrm{m}$, it can be noticed that gain value will be $26.40 \mathrm{~dB}$ and NF $3.18 \mathrm{~dB}$ when the input power is 10 $\mathrm{dBm}$. These values of gain and noise figure provide an optimum Q factor around 57.53 for EDFA in-line amplifier. However, concentration $\mathrm{C}=1 \mathrm{e}+25 / \mathrm{m}^{-3}$, $\mathrm{L}_{\text {edfa }}=3 \mathrm{~m}$ and $\mathrm{D}=2.2 \mu \mathrm{m}$ provide a high gain $\mathrm{G}$ of $31.53 \mathrm{~dB}$ and noise figure NF $3.27 \mathrm{~dB}$. Those values can provide the optimum EDFA used in position preamplifier with $\mathrm{Q}=6.24$
3. Other, the output parameters like $\mathrm{Q}$ factor, eye diagrams for booster, pre-amplifier and in-line amplifier are compared versus different parameter (splitter loss, signal input power and fiber length...). From the simulation results, it is found that as the fiber length increases, the $\mathrm{Q}$ factor decreases. Also in the term of $\mathrm{Q}$ factor, the in-line amplifier has the best performance followed by post- amplification (booster) and lower value for pre-amplifier.

\section{REFERENCES}

[1] Ioannis P Chochliouros George A Heliotis."Optical Access Networks and Advanced Photonics: Technologies and Deployment Strategies" .BookFi.org.

[2] Josep Prat “ Next-Generation FTTH Passive Optical Networks " Springer BookFi.org

[3] ITU-T Recommendation G.984.1, "Gigabit-capables passive optical network (GPON)", ITU, 2008.

[4] S. Pato, J. Santos, J. Pedro, P. Monteiro and H. Silva, "On Supporting Radio over Fiber and Passive Optical Network Systems with a Common Fiber Plant: Compatibility Aspects," Proceeding of ITCON, 2008

[5] Dheyaa J. Kadhim "Performance Analysis of xPON Network for Different Queuing Models", International Journal of Electrical, Electronics and Telecommunication Engineering April 2013

[6] G. E. R. de Paiva, M. M. Freire, U. R. Duarte, A. B. Sassi, A. C. Bizetti, J. F. Pozzuto, J. B. M. A. Romero Rosolem," $80 \mathrm{~km}$ Extended Gigabit Passive Optical Network". IEEExplore.ieee.org. 2011.

[7] Joindot, M., 2000. "Transmission systems on optical fiber treatise of telecommunications: TE 7115”, pp: 6-9

[8] krzysztof iniewski carl mccrosky daniel minoli. "Network infrastructure and architecture designing highavailability networks" pp:56

[9] Ivica Cale, Aida Salihovic, Matija Ivekovic, Gigabit Passive Optical.

[10] Arie Golberg. "Carrier Ethernet over GPON and EP2P" Omnitrons Systems Technology, Inc. 2008.

[11] Cedric F. Lam “ Passive Optical Network” BookFi.org

[12] Network-GPON. Conf. On Information Technology Interfaces, Jun. 25-28. 2007.

[13] C. H. Yeh1, C. W. Chow2, Y. M. Lin1, D. Z. Hsu1, and S. Chi2 ,"Recent Research on Fiber Access Systems for FTTH Networks in Taiwan", IEEE . April 2008 